\title{
LAS ARTISTAS EXILIADAS EN MÉXICO Y SUS DESCENDIENTES EN LAS BASES DE DATOS. ANÁLISIS Y PROPUESTA
}

The artists exile in Mexico and their descendants in the databases. Analysis and proposal

\author{
Yolanda Guasch Marí \\ Universidad de Granada \\ yguasch@ugr.es \\ Orcid: 0000-0001-9447-065X
}

Recibido: 03-11-2020 - Aceptado: 02-03-2021

Cómo citar este artículo/Citation:
Yolanda Guasch Marí, "Las artistas exiliadas en México y
sus descendientes en las bases de datos. Análisis y
propuesta", Hispania Nova, 1 Extraordinario (2021): 122 a
151.
DOI: $\underline{\text { https://doi.org/10.20318/hn.2021.6181 }}$

DOI: https://doi.org/10.20318/hn.2021.6181
Copyright: (C) HISPANIA NOVA es una revista debidamente registrada, con ISSN 1138-7319 y Depósito Legal M 9472-1998. Los textos publicados están -si no se indica lo contrario- bajo una licencia Reconocimiento-Sin obras derivadas 3.0 España de Creative Commons. Puede copiarlos, distribuirlos y comunicarlos públicamente siempre que cite su autor y la revista y la institución que los publica y no haga con ellos obras derivadas. La licencia completa se puede consultar en: http://creativecommons.org/licenses/by-nd/3.0/es/deed.es

\begin{abstract}
Resumen: En este artículo analizamos las bases de datos existentes en la red sobre mujeres artistas y la presencia en ellas de las exiliadas en México tras el conflicto español, justificando la necesidad de crear una base de datos en línea, en acceso abierto, que visualice de igual forma su trabajo y se convierta en otro espacio que permita el acercamiento a las publicaciones sobre las mismas, la ubicación de las obras más representativas o la biografía, entre otros aspectos, con el fin de generar nuevas miradas que contribuyan, en definitiva, a su conocimiento.
\end{abstract}

Palabras clave: Artistas; Bases de datos; Exilio; México; Propuesta.

\begin{abstract}
In this article we analyze the existing databases on the network on women artists and the presence in them of the exiles in Mexico after the Spanish conflict, justifying the need to create an online database, in open access, that can be viewed equally form their work and become another space that allows the approach to publications about them, the location of the most representative works or the biography, among other aspects, in order to generate new views that contribute, in short, to your knowledge.
\end{abstract}

Keywords: Artists; Databases; Exile; Mexico; Proposal. 


\section{INTRODUCCIÓN}

Las Humanidades Digitales están permitiendo nuevas metodologías de investigación aplicadas a la Historia del Arte pero también, y no menos importante, están generando propuestas alternativas para la transferencia y la difusión de los resultados. Como apunta Nuria Rodríguez aunque han sido los museos "uno de los contextos en los que más se ha innovado en los procesos digitales relacionados con la producción, distribución y resemantización de la cultura artística"1, la misma autora enfatiza que en la actualidad una generación de historiadores e historiadoras del arte en sus estudios, "están aplicando nuevas estrategias de análisis para repensar los hechos artísticos desde parámetros vinculados fundamentalmente a las potencialidades del procesamiento computacional de grandes conjuntos de datos; los análisis de redes; la distribución y representación geoespacial; las nuevas visualizaciones de información que proveen el medio digital; el desarrollo de nuevas narrativas multimodales etc" ${ }^{2}$.

En línea con las nuevas herramientas de compartir, editar y distribuir información y con el objetivo de hacer llegar la investigación académica a más audiencia que la propia comunidad científica, nos planteamos en qué medida podemos contribuir desde las Humanidades Digitales a la transferencia y difusión de la investigación sobre una de nuestras líneas prioritarias dedicadas al estudio de mujeres pintoras exiliadas en México tras la Guerra Civil española, así como las artistas descendientes de este éxodo. Esta área de trabajo se inserta en un campo de conocimiento cuya literatura científica está siendo prolífica en los últimos años, tanto en cantidad como en calidad ${ }^{3}$. En el terreno específicamente de las exiliadas advertiremos, también, que poco a poco sus trayectorias han ido emergiendo de la opacidad en la que se encontraban siendo visibles el reconocimiento e integración en la Historia del Arte que ya goza alguna de ellas.

Sin embargo, si necesaria es la investigación no menos importante es la

\footnotetext{
${ }^{1}$ Nuria Rodríguez-Ortega, "Humanidades Digitales, Digital Art History y cultura artística: relaciones y desconexiones", Artnodes, 13 (2013): 20, doi: 10.7238/a.v0i13.2017. Sobre Humanidades Digitales e Historia del Arte, además de esta cita, véanse otras publicaciones de la misma autora en Nuria RodríguezOrtega, https://uma.academia.edu/NuriaRodr\%C3\%ADguez.

${ }^{2}$ Ibídem.

${ }^{3}$ Sobre este tema cfr, entre otros, el trabajo de Pilar Muñoz, "Las publicaciones y la investigación sobre mujeres artistas en España”, Revista de Estudios de las Mujeres, 3 (2015), 317-338.
} 
transferencia y la difusión. De entrada advertimos que estos últimos procesos, posiblemente, no poseen la misma fortaleza que el primero en el caso de las mujeres artistas ya que, como apuntan algunas publicaciones, convendría repensar los discursos expositivos de los museos o los temarios de Historia del Arte de las universidades ${ }^{4}$. De hecho es precisamente en estos espacios de conocimiento donde todavía existe cierta rigidez y descuido por activar mecanismos de cambio y generar nuevas estrategias y acciones más visibles que representen las demandas de la sociedad. Es cierto que, como indica Riaño ${ }^{5}$, "con la historiografía feminista ha habido un movimiento de tierras que también está reeducando a las personas que dirigen los museos $\mathrm{y}$, de hecho, ya se aprecian algunos pasos en la National Gallery de Londres, la Tate Liverpool o el Musée d'Orsay" ". En este intento de mostrar el cambio museos como la National han activado la maquinaria para contribuir a esta transformación con la compra de obras como la adquisición del autorretrato de Artemisa Gentileschi ${ }^{7}$. Sin embargo, también es cierto que todavía queda un largo camino por recorrer. Parafraseando a Octavio Salazar se hace necesario

\begin{abstract}
"poner el dedo de la igualdad en la llaga de la cultura y desmantelar toda una estructura a través de la cual el patriarcado se mantiene y se reinventa... [...]. Es urgente, pues, que también los museos... se conviertan en espacios de superación de determinados discursos e imaginarios, que ofrezcan no solo la mirada creativa de las mujeres en igualdad de condiciones con los hombres, sino que también revisen los argumentos y los esquemas mediante los que han construido un espacio, que diría Iris Marion Young de "imperialismo cultural".
\end{abstract}

Si bien es cierto que este panorama puede parecer desalentador, debemos precisar que se han puesto en marcha iniciativas de cualidad diversa que tratan de paliar la profunda grieta, desde una perspectiva de género, mantenida en nuestra Historia del Arte. Junto a investigaciones científicas, análisis cuantitativos, exposiciones específicas

\footnotetext{
${ }^{4}$ Aunque se han hecho algunos esfuerzos como la creación de materias como "Arte y Género".

${ }^{5}$ Peio H. Riaño, Las invisibles. ¿Por qué el Museo del Prado ignora a las mujeres? (Madrid: Capitán Swing, 2020).

${ }^{6}$ Ianko López, "Represión y liberación: cuando el arte se usó para aleccionar a las mujeres (y cómo ellas le han dado la vuelta)", El País, Icon Design, 4 de marzo de 2020.

${ }^{7}$ La pintora barroca, de origen italiano, goza en la actualidad de un incesante interés que se manifiesta en el número de exposiciones y publicaciones recientes.

${ }^{8}$ Octavio Salazar, “Las invisibles. Rebelión desde el confinamiento”, El País, 3 de abril de 2020.
} 
sobre féminas, y en un intento de mejorar su reconocimiento, la difusión de la labor de estas artistas en bases de datos en línea ${ }^{9}$ se ha convertido en el instrumento perfecto para su visibilidad en red ${ }^{10}$ y plataforma directa hacia la sociedad en general.

En este artículo partiendo de la situación historiográfica de las artistas exiliadas así como la transferencia de la investigación a través de exposiciones y la evaluación de su presencia en museos como ejemplo concreto de difusión, analizamos las bases de datos existentes en la red sobre mujeres artistas y la presencia en ellas de las exiliadas en México tras el conflicto español, integrando además a las descendientes de este exilio, justificando la necesidad de crear una base de datos en línea, en acceso abierto, que represente de igual forma su trabajo y se convierta en otro espacio que permita el acercamiento a las publicaciones sobre las mismas, el intercambio de fuentes, la ubicación de las obras más representativas o una aproximación biográfica a todas ellas, entre otros aspectos, con el fin de generar nuevas miradas que contribuyan, en definitiva, a su conocimiento.

\section{MUJERES ARTISTAS ESPAÑOLAS EXILIADAS. BREVE ESTADO DE LA CUESTIÓN}

Como ya hemos apuntado la investigación, la transferencia del conocimiento y la difusión, conforma un sistema imbricado que permite relacionar a la academia con la ciudadanía. En este sentido, en este apartado examinamos la situación historiográfica del estudio de las creadoras exiliadas, la transferencia de este conocimiento a través de un caso concreto, como son las exposiciones individuales y colectivas y su inclusión, o exclusión, de sus obras en museos, espacios esenciales, por antonomasia, para la difusión cultural.

\footnotetext{
${ }^{9}$ El fenómeno se ha extendido a muchos campos del saber y con objetivos muy diversos, como la impulsada por la Asociación de mujeres investigadoras y tecnólogas quienes han creado una base de datos de científicas para hacer accesible el talento femenino de todas las áreas de la ciencia, cfr. Base de datos de mujeres investigadoras y tecnólogas, (https://cientificas.amit-es.org/).

${ }^{10}$ Otro tema de interés, en el que estamos en proceso, es analizar la presencia de las artistas exiliadas en las redes sociales ya que canales como Twitter se han convertido en el canal más utilizado por los museos de arte contemporáneo. Su uso se debe, principalmente, a que "ofrece noticias breves y concisas, fácilmente legibles y asimilables por el gran público" convirtiéndose en otra experiencia de gran interés. Así lo demuestran trabajos como el de Susana del Cerro Herrero y Esther Meneses Ruiz de los Paños, "Iniciativas para la difusión del arte en Twitter en España. El proyecto de @UnDiaUnaObra", ArtyHum, Revista Digital de Artes y Humanidades, 1 (2015), 77.
} 
Los estudios de las mujeres artistas españolas del siglo XX, especialmente de las protagonistas de las primeras décadas, han generado en los últimos años una creciente literatura científica que pone de manifiesto el interés y la pertinencia del tema ${ }^{11}$, originándose escritos específicos, también, sobre las artistas exiliadas en América Latina como el realizado por Carmen Gaitán, Las artistas del exilio republicano español. El refugio latinoamericano ${ }^{12}$, que abarca por primera vez el legado de estas creadoras en Argentina, Chile y México. Es precisamente en este último territorio donde se concentra un grupo mayoritario con respecto al resto de las geografías mencionadas. Aunque no es el tema de este artículo, no debemos olvidar que esta mayor representación está determinada, entre otros factores, por las propias condiciones ofrecidas por el país mexicano al exilio español.

Un destierro que a nivel artístico propició uno de los intercambios culturales más importantes y de más trascendencia del siglo XX y cuyo interés, a día de hoy, continúa más vigente que nunca. La recuperación de las aportaciones del exilio se ha ido manteniendo, fundamentalmente, a través de los aniversarios y las conmemoraciones que han favorecido en el terreno artístico, además de congresos y publicaciones, la producción de exposiciones. Un campo de acción y divulgación, incluso de recuperación de la memoria que se inició en México y con la llegada de la democracia, también, en España. A través de estas muestras, junto con los estudios dedicados específicamente a las artes plásticas, hemos podido ir elaborando un listado de creadoras exiliadas, así como de las descendientes del exilio ${ }^{13}$, que aún nacidas en el país mexicano han sido consideradas así por la historiografía especializada. Por lo tanto, su inclusión en alguna muestra específica sobre el exilio español ${ }^{14}$ nos ha llevado a trabajar

\footnotetext{
${ }^{11}$ Véase, entre otras, Almudena de la Cueva y Margarita Márquez Padorno (eds.), Mujeres en vanguardia, La residencia de Señoritas en su centenario [1915-1936] (Madrid: Residencia de Estudiantes, 2015) o Mercedes Gómez-Blesa, Modernas y Vanguardistas. Las mujeres-faro de la modernidad (Madrid: Huso Ensayos, 2019), entre los más recientes.

12 Carmen Gaitán Salinas, Las artistas del exilio republicano español. El refugio latinoamericano (Madrid: Cátedra, 2019).

${ }^{13}$ Este trabajo se ha realizado en el marco del proyecto de investigación Diccionario Biográfico ilustrado de mujeres artistas en México. Siglos XIX y XX, dirigido por las investigadoras Elisa García Barragán y Leticia López Orozco, del Instituto de Investigaciones Estéticas de la Universidad Nación Autónoma de México que se puso en marcha en el año 2010. Cfr. Instituto de Investigaciones Estéticas, Universidad Nacional Autónoma de México, http://www.esteticas.unam.mx/mujeres artistas.

${ }^{14}$ En el año 1989 se realizó en México, coincidiendo con el aniversario del 50 Aniversario del Exilio Español, la primera gran muestra de obra plástica en el Museo de San Carlos. Fernando Gamboa
} 
no solo con creadoras exiliadas en el sentido estricto de la palabra sino, además, con aquellas herederas que han sido valoradas en el amplio y heterogéneo grupo de creadores y creadoras. Por poner solo un ejemplo, en la magna exhibición acometida en España en el conmemorativo año 2019, bajo el título 1939, Exilio republicano español, se han presentado pinturas de Manuela Ballester, Remedios Varo, Elvira Gascón, además de Mary Martín, Marta Palau o María Teresa Toral, que llegaron siendo niñas al país mexicano o mucho más tarde, en el caso de Toral, de las fechas del gran éxodo. Esta nómina de féminas se amplia en el catálogo con un texto específico sobre mujeres artistas en el que se añaden, entre las exiliadas a México y además de las ya citadas, los nombres de Carmen Cortès, Juana Francisca Rubio, Soledad Martínez, Elisa Piqueras, Alma Tapia, Elena Verdes Montenegro, Paloma Altolaguirre, Rosa Ballester, Josefina Ballester, Maruja Bardasano, Regina Raull, Lucinda Urrusti, Montserrat Aleix, Julia Giménez Cacho o Isabel Richart, entre otras ${ }^{15}$.

Por lo tanto basándonos en estos estudios, el número de mujeres analizadas es muy amplio y diverso -pluralidad de temas, estéticas, edades, educación- y no puede generalizarse su manera de entender y manifestar su condición de exiliadas que se mantiene, en cualquier caso, por el hecho de vivir en un entorno que generó en el caso de México, la permanencia de una España trasplantada, o transterrada como acuñó José Gaos, simbolizada con la creación de escuelas, organizaciones culturales o asociaciones propias de las que directa o indirectamente formaron parte las artistas integradas en este trabajo. Esta misma realidad puede aplicarse al estudio de los artistas varones donde,

introducía un texto aportando nombres de muchos creadores y entre las mujeres rendía tributo a Remedios Varo, Elvira Gascón y más jóvenes que ellas y vivas aún, Lucinda Urrusti, Marta Palau y Paloma Altolaguirre. Manuel Ulacia era el encargado de escribir las líneas que explicaban las tres secciones que constituían la muestra, cuyo tercer espacio estaba dedicado o integrado por "los artistas que llegan a México en la infancia. Todos ellos se educan en el país y sus obras forman parte, en la actualidad, de la pintura contemporánea mexicana. Este grupo se distingue por haber integrado en sus obras la tradición mexicana con la española, así como por haber dialogado con la tradición internacional”. Cfr. Manuel Ulacia, "Los pintores del exilio español en México" ed. Por AA.VV., 50 Aniversario del Exilio Español (1939-1989) (México: Museo de San Carlos, 1989), 11. Además, en la muestra se presentaban telas de Montserrat Aleix, Josefina Ballester, Manuela Ballester, Loty de la Granja, Julia Giménez Cacho, Mary Martín, Regina Raull y María Teresa Toral. A partir de entonces se han sucedido las exposiciones que han ido seleccionando nombres condicionados, a veces, por criterios extra-artísticos, pero que en cualquier caso han permitido ampliar la nómina de féminas creadoras.

${ }^{15}$ Cfr. Carmen Gaitán Salinas, "Ellas también fueron artistas: las españolas del exilio republicano en América Latina", coord. por Juan Manuel Bonet, 1939. Exilio republicano español. (Madrid: Ministerio de Justicia, 2019), 445-452. 
también, se incluyen nombres que no son exiliados entendidos estos como expatriados, generalmente, por motivos políticos.

Teniendo en cuenta lo expuesto y situado nuestro punto de partida, al abordar el estudio de las creadoras españolas en México uno de los primeros obstáculos que debemos afrontar son los pocos datos que aparecen de ellas en compendios generales sobre arte, que todavía no han incluido, de forma generalizada, su importancia. Pero, además, cuando lo han hecho, se ha sumado la dificultad de poder desvincular sus nombres al de los hombres como "esposas de", "hermanas de" o "hijas de", categorizaciones muy utilizadas en la historia del arte. Este hecho se presenta, en muchas ocasiones, en aquellas autoras nacidas en un entorno familiar artístico o cuyos maridos son creadores, también, como ocurre con la valenciana Manuela Ballester pareja de Josep Renau, hermana de Tonico Ballester e hija de Antonio Ballester Aparicio, quien fue escultor y profesor de la Escuela de Bellas Artes de Valencia. Igualmente sucede con la madrileña Juana Francisca Rubio esposa de José Bardasano. En otros casos la utilización del apellido marital o una mayor proyección pública del cónyuge provoca, igualmente, un menor reconocimiento de la artista. En este sentido no son excepciones casos como el de la catalana Carmen Cortès conocida, a la vez, con el nombre de Carmen d'Aguadé por ser compañera del que fue alcalde de la ciudad de Barcelona, Jaime Aguadé; o la madrileña Margarita González Giraud, formada con el pintor José Frau con quien se casaría y tomaría su apellido, conociéndose a partir de entonces como Margarita de Frau.

Esta vaga representación de las mujeres artistas exiliadas, como decíamos, en la bibliografía general, tanto la dedicada al arte contemporáneo del siglo XX español y mexicano, como la centrada en el arte español del exilio, ha sido resarcida con la publicación de monografías específicas. Aunque todavía contamos con pocos ejemplos concentrados fundamentalmente en la figura de Remedios Varo ${ }^{16}$, son importantes los estudios concretos que se han realizado sobre Manuela Ballester ${ }^{17}$, Elvira Gascón ${ }^{18}$,

\footnotetext{
${ }^{16}$ Entre los trabajos más recientes encontramos Magnolia Rivera, Trampantojos. El círculo en la obra de Remedios Varo (México: Siglo XXI, 2005); Andrea Luquin Calvo, Remedios Varo: el espacio y el exilio. (Alicante, Centro de Estudios sobre la mujer/Universidad de Alicante, 2009); o Masayo Nonaka, Remedios Varo: Los años en México. (México, Ediciones RM, 2012).

${ }^{17}$ Manuel García (ed.), Homenatge a Manuela Ballester. (Valencia, Generalitat Valenciana, Consellería de Trabajo y Asuntos Sociales, Dirección General de la Mujer, 1996.
} 
Soledad Martínez ${ }^{19}$, María Teresa Toral ${ }^{20}$ y entre las más jóvenes todavía en activo, Marta Palau ${ }^{21}$ y Lucinda Urrusti ${ }^{22}$.

Junto a estos trabajos científicos, otro de los aspectos sobre el que hemos puesto atención en nuestra investigación ha sido analizar su presencia en exposiciones individuales y colectivas, realizadas tanto en vida o tras su fallecimiento. Evidentemente las trayectorias artísticas de cada una de ellas, como ocurre con los exiliados varones, fueron muy amplias y estuvieron determinadas por contextos y realidades muy diferentes. Las que comenzaron en España vivieron los años de la II República que generó nuevas oportunidades para ellas, pero, a la vez, con el exilio se vieron obligadas a adaptarse a un nuevo territorio donde, incluso, tuvieron que asumir otros roles en detrimento de su profesión como pintoras, como el caso de Margarita de Frau. Algunas de las que se formaron en México lo hicieron con maestros exiliados y mexicanos, como el caso de Mary Martín. Otras, en cambio, recibieron una formación plenamente mexicana pero la experiencia del exilio ha permanecido y se ha resignificado de forma distinta, como se aprecia en la artista Marta Palau y su serie "Homenaje a Lázaro Cárdenas".

Algunas como Remedios Varo o la propia Palau, han tenido una proyección más internacional y otras, en cambio, solamente formaron parte de exhibiciones y espacios creados por el propio exilio, por lo que su ámbito de acción se mantuvo en los círculos españoles. Sin embargo, desde sus múltiples contextos, con sus limitaciones y oportunidades, han contribuido a mostrar las distintas consecuencias del exilio.

En definitiva, las exposiciones y la crítica especializada derivada de las mismas, nos permiten comprender su proyección artística en el escenario mexicano que determinará una mayor o menor participación en la esfera pública $\mathrm{y}$, por tanto, el conocimiento de sus trayectorias tanto en nuestro territorio como en México que favorece la inclusión de sus nombres en la historia del arte o, al contrario, ha provocado

\footnotetext{
18 Mauricio César Ramírez Sánchez, Elvira Gascón. La línea de una artista en el exilio. (México: El Colegio de México, 2014).

19 AA.VV., La pintora Soledad Martínez y sus coleccionistas (Valencia: Talleres Gráficas Ripoll, 1991).

${ }^{20}$ Yolanda Guasch Marí y María José Montañés, María Teresa Toral. Obra Gráfica. (Alcalá la Real: Asociación Enrique Toral y Pilar Soler, Ayuntamiento de Andújar, 2012).

${ }^{21}$ Rita Eder, Marta Palau. La intuición y la técnica. (Michoacán: Gobierno de Michoacán, 1985).

${ }^{22}$ Eduardo Espinosa Campos, Lucinda Urrusti. Pintora de la luz. (México: Círculo del Arte, 2008).
} 
el absoluto olvido. Como ejemplo claro de estos aspectos, y sin entrar en un examen exhaustivo y profundo de los lugares en los que expusieron las artistas aquí tratadas ${ }^{23}$, basta con señalar que para la trayectoria de Elvira Gascón, Lucinda Urrusti o Marta Palau fue significativa su presencia en el Palacio de Bellas Artes, considerada la máxima institución cultural y reservada a las grandes figuras de México. La primera muestra materializada sobre una exiliada, fue la antológica sobre Remedios Varo realizada en 1964, solo un año después de su muerte. En la década de los setenta, en 1973, se celebró otra sobre Lucinda Urrusti con el título Pinturas y dibujos. Un año después, en 1974, se inauguró Marta Palau. Del tapiz a la escultura y en 1977, Elvira Gascón. Óleos, tintas, dibujos, grabados, esmaltes. En la década de los 80 se presentaría una nueva exhibición de la catalana Marta Palau, con el título Marta Palau. Mis caminos son terrestres. Muros, esculturas, ambientaciones en fibra ${ }^{24}$.

La repercusión de estas tres pintoras en el escenario cultural mexicano fue muy diferente a la de casos como Rosa y Josefina Ballester, de quienes hemos documentado muy pocas muestras, o de Elena Verdes-Montenegro quien, aunque pintó de forma continuada, se centró en otras labores como la restauración y la docencia en México.

En definitiva, la publicación de investigaciones más completas -como la citada de Carmen Gaitán con visión generalista, pero conectando todas las trayectorias- así como otros aportes que se han hecho a partir de artículos y capítulos de libros o catálogos de exposiciones con una clara intención de romper con los estereotipos o clasificaciones, nos están permitiendo conocer con más rigor sus trayectorias y seguir construyendo en positivo ${ }^{25}$. No obstante, todavía son necesarias abrir otras vías de

\footnotetext{
${ }^{23}$ Estamos trabajando en un estudio exhaustivo de exposiciones, espacios expositivos y países donde se han celebrado estas muestras, incluyendo la relación de obras expuestas y la crítica generada en torno a ellas. Este trabajo se ha realizado gracias a numerosas estancias de investigación en México que nos han permitido consultar los catálogos de los museos y galerías más representativas del país mexicano. Igualmente hemos accedido a los archivos personales que nos han ayudado a completar la información.

${ }^{24}$ En el mismo espacio han presentado su obra pintoras como Elena Climent, nacida en México y mucho más joven que todas ellas, en 1988 con el título Elena Climent. Flor de Asfalto. Asimismo, aunque con una proyección e importancia mucho menor en sus trayectorias, a través de colectivas se han mostrado obras de Puri Yáñez, que formó parte de la muestra El Autorretrato, realizada en 1967, y de las artistas Paloma Altolaguirre y Rosa Ballester en la primera Bienal de Artes Gráficas, celebrada en 1977. Sobre las exposiciones celebradas en el Palacio de Bellas Artes, cfr. AA.VV., Museo del Palacio de Bellas Artes. (México: CONACULTA, 2012), 204-263. Las exposiciones reseñadas en este libro corresponden a la etapa 1934-2012.

${ }^{25}$ Aunque sin olvidar que existen todavía imprecisiones sobre alguna creadora como el caso de la murciana Puri Yáñez, de quien aún no se conoce la fecha de muerte o de Carme Millà, de quien es difícil
} 
indagación que permitan, entre otras cosas, continuar localizando y documentando muchas de las obras que se ubican en colecciones privadas o, inclusive, evidenciar nuevos nombres.

En la siguiente tabla, de manera sintetizada, presentamos algunos resultados parciales del trabajo realizado hasta el momento en el que ya hemos analizado las proyecciones públicas de estas artistas en el contexto cultural español y mexicano a través de las exposiciones, individuales y colectivas y de las que demostramos el resultado obtenido de los últimos veinte años. Igualmente se ha rastreado su representación en publicaciones de ambas geografías, determinando las que tienen una monografía. Finalmente, aunque este apartado está todavía en curso, hemos localizado y documentado qué artistas están incorporadas con obras en museos españoles o en los ubicados en el territorio mexicano ${ }^{26}$.

\begin{tabular}{|c|c|c|c|c|c|}
\hline Nombre & $\begin{array}{c}\text { Exposiciones } \\
\text { individuales } \\
\text { (2000-2020) }\end{array}$ & $\begin{array}{c}\text { Exposiciones } \\
\text { colectivas } \\
\mathbf{( 2 0 0 0 - 2 0 2 0 )}\end{array}$ & $\begin{array}{c}\text { Publicaciones } \\
\text { colectivas }\end{array}$ & Monografías & $\begin{array}{c}\text { Obra en } \\
\text { museos }\end{array}$ \\
\hline $\begin{array}{c}\text { Montserrat, Aleix } \\
(1908-2004)\end{array}$ & Sí & Sí & Sí & No & Sí \\
\hline $\begin{array}{c}\text { Altolaguirre, Paloma } \\
(1935)\end{array}$ & No & Sí & Sí & No & Sí \\
\hline $\begin{array}{c}\text { Ballester Vilaseca, Josefina } \\
(1925-2005)\end{array}$ & No & No & Sí & No & Sí \\
\hline $\begin{array}{c}\text { Ballester Vilaseca, } \\
\text { Manuela } \\
(1908-1994)\end{array}$ & Sí & Sí & Sí & Sí & Sí \\
\hline $\begin{array}{c}\text { Ballester Vilaseca, Rosa } \\
(1919-1988)\end{array}$ & No & Sí & No & Sí \\
\hline
\end{tabular}

trazar un biografía completa más allá de los datos publicados, entre otros, por Santi Barjau en una entrada de su blog. Cfr. Els meus cartellistes. El blog d'història del cartell de Santi Barjau. http://cartellistes.blogspot.com/2012/11/els-cartellistes-del-sindicat-de.html. Para conocer la trayectoria de Puri Yáñez, cfr. Carmen Gaitán Salinas, Las artistas del exilio republicano español..., op. cit., págs. 272-275.

${ }^{26}$ La localización de obras en instituciones culturales, tanto en México como en España, es un trabajo que está en curso. No obstante, los museos más importantes de ambos territorios ya han sido analizados. En el caso del país mexicano las instituciones consideradas situadas en la capital han sido: Ateneo Español de México, Colección Banco Nacional de México, Colección El Colegio de México, Colección El Colegio Nacional, Colección Pago en Especie de la Secretaría de Hacienda y Crédito Público, Museo de Arte Moderno, Museo Carrillo Gil, Museo Nacional de la Estampa, Museo Rufino Tamayo, Museo Universitario de Arte Contemporáneo, Museo Universitario del Chopo, Museo Universitario de Ciencias y Artes, Museo Soumaya y Colección Kaluz. En cuanto a España, se han analizado el Instituto valenciano de Arte Moderno, Museu d'Art de Sabadell, Museo de Arte Contemporáneo "Vicente Aguilera Cerni", (Villafamés), Museo de L'Empordà (Figueras), Museo Hispano-Mexicano de Alagón, Museo Municipal de Tossa del Mar, Museo Nacional Centro de Arte Reina Sofía, Museo Nacional de Cerámica "González Martí" (Valencia), Museo Ramón Gaya (Murcia), Real Academia de Bellas Artes de San Carlos (Valencia) y Real Academia de Bellas Artes de San Fernando (Madrid). 
YOLANDA GUASCH MARÍ

Las artistas exiliadas en México y sus descendientes en las bases de datos. Análisis y propuesta

\begin{tabular}{|c|c|c|c|c|c|}
\hline Nombre & $\begin{array}{c}\text { Exposiciones } \\
\text { individuales } \\
(2000-2020)\end{array}$ & $\begin{array}{l}\text { Exposiciones } \\
\text { colectivas } \\
(2000-2020)\end{array}$ & $\begin{array}{c}\text { Publicaciones } \\
\text { colectivas }\end{array}$ & Monografías & $\begin{array}{c}\text { Obra en } \\
\text { museos }\end{array}$ \\
\hline $\begin{array}{l}\text { Climent Smoland, Elena } \\
\text { (1955) }\end{array}$ & Sí & Sí & Sí & Sí & Sí \\
\hline $\begin{array}{c}\text { Cortès Lledó, Carmen } \\
(1892-1979)\end{array}$ & No & Sí & Sí & No & Sí \\
\hline $\begin{array}{c}\text { Gascón Pérez, Elvira } \\
(1911-2000)\end{array}$ & Sí & Sí & Sí & Sí & Sí \\
\hline $\begin{array}{c}\text { Giménez Cacho, Julia } \\
(1921-2000)\end{array}$ & Sí & No & Sí & No & No \\
\hline $\begin{array}{c}\text { González Giraud, } \\
\text { Margarita } \\
(1910-1986)\end{array}$ & No & No & Sí & No & Sí \\
\hline $\begin{array}{c}\text { Granja, Loty de la } \\
\text { (1934) }\end{array}$ & No & No & Sí & No & Sí \\
\hline $\begin{array}{c}\text { Martín Iglesias, María } \\
\text { Luisa } \\
(1927-1982)\end{array}$ & No & Sí & Sí & No & No \\
\hline $\begin{array}{c}\text { Martín Arroyo, María } \\
\text { Teresa } \\
(1936)\end{array}$ & Sí & Sí & No & No & Sí \\
\hline $\begin{array}{c}\text { Martínez García, Soledad } \\
(1900-1996)\end{array}$ & Sí & Sí & Sí & Sí & Sí \\
\hline $\begin{array}{c}\text { Millà Tersol, Carme } \\
(1907-1999)\end{array}$ & No & Sí & Sí & No & No \\
\hline $\begin{array}{c}\text { Muñoz Montoro, Amparo } \\
(1904-1989)\end{array}$ & No & No & Sí & No & No \\
\hline $\begin{array}{c}\text { Olabuenaga Martín, María } \\
\text { Teresa (1958) }\end{array}$ & Sí & Sí & Sí & No & Sí \\
\hline $\begin{array}{c}\text { Palau } \\
\text { Bosch, Marta (1934) }\end{array}$ & Sí & Sí & Sí & Sí & Sí \\
\hline $\begin{array}{c}\text { Piqueras Lozano, Elisa } \\
\text { (1912-1974) }\end{array}$ & No & Sí & Sí & No & No \\
\hline $\begin{array}{c}\text { Raull Martín, Regina } \\
\text { (1931-2019) }\end{array}$ & No & Sí & Sí & No & Sí \\
\hline $\begin{array}{c}\text { Rubio García, Juana } \\
\text { Francisca } \\
(1911-2008)\end{array}$ & No & Sí & Sí & No & Sí \\
\hline $\begin{array}{c}\text { Toral Peñaranda, María } \\
\text { Teresa } \\
(1911-1995)\end{array}$ & Sí & Sí & Sí & Sí & Sí \\
\hline $\begin{array}{c}\text { Urristi Sanz, Lucinda } \\
\text { (1929) }\end{array}$ & Sí & Sí & Sí & Sí & Sí \\
\hline $\begin{array}{c}\text { Varo Uranga, Remedios } \\
(1908-1963)\end{array}$ & Sí & Sí & Sí & Sí & Sí \\
\hline $\begin{array}{c}\text { Verdes-Montenegro } \\
\text { Martín, Elena } \\
(1906-1995)\end{array}$ & No & No & Sí & No & No \\
\hline $\begin{array}{c}\text { Yáñez Egea, Purificación } \\
(1935-i ?)\end{array}$ & No & No & Sí & No & No \\
\hline
\end{tabular}

Fuente: Análisis de la presencia de artistas exiliadas y sus descendientes en libros, muestras individuales y colectivas y museos españoles y mexicanos. Elaboración propia. 
Como puede apreciarse en la tabla, todo el conjunto de artistas consideradas han sido todas introducidas en alguna publicación colectiva ${ }^{27}$. En cambio, si analizamos cuántas de ellas tienen monografía, como ya apuntábamos, el número se reduce considerablemente.

En cuanto a su presencia en instituciones culturales, públicas o privadas, más del $50 \%$ de las creadoras están representadas con sus producciones en algún museo o colección. Sin embargo, esta información es matizable ya que las obras de muchas de ellas estrictamente se localizan en el Ateneo Español de México, como serían los casos de Loty de la Granja o María Teresa Martín. Este organismo fundado por el exilio, en 1949, alberga en la actualidad una colección de más de 400 obras $^{28}$, lo que la sitúa en el acervo más importante sobre las artistas del exilio en el país mexicano.

Le sigue muy de cerca una colección privada que hace muy poco tiempo se ha hecho pública a través de la fundación del Museo Kaluz. Este espacio, inaugurado en el 2020, presenta parte del acervo de Antonio del Valle. En ella se rastrean los propios gustos del coleccionista centrados en dos grandes temas, la pintura figurativa mexicana, por un lado, y el arte del exilio español, por otro, con representación de tres mujeres: Elvira Gascón, Lucinda Urrusti y Manuela Ballester ${ }^{29}$.

Ahora bien, si buceamos en los museos más representativos de la Ciudad de México sobre arte contemporáneo, la presencia de las creadoras españolas es muy escasa. De los espacios públicos analizados hasta el momento, el Museo de Arte Moderno solamente alberga telas de Remedios $\operatorname{Varo}^{30}$ o el Museo Nacional de la Estampa, que atesora varios grabados de María Teresa Toral. De gestión privada, el Museo Soumaya conserva una tela de Manuela Ballester. Para casos como el de la pintora Carmen Cortès, hay que buscar su obra en Monterrey, ciudad en la que vivió

\footnotetext{
${ }^{27}$ Aunque hay que advertir que la mayoría aparece en el libro de Carmen Gaitán Salinas, Las artistas del exilio..., op. cit.

28 José María Espinasa y Teresa Olabuenaga (textos), Colección plástica del Ateneo Español de México. 70 Años de pluralidad. (México: Ateneo Español de México A.C., 2018).

${ }^{29}$ Véase José Ignacio Aldama, "La colección Kaluz”, ed. por Elena Horz Balbás, La colección Kaluz. (México: Horz Asociados, 2018), 12-13.

${ }^{30}$ Para la colección de Remedios Varo más importante de México, donada por Walter Gruen, cfr. Museo de Arte Moderno de México, https://mam.inba.gob.mx/coleccion-archivo.
} 
durante algunos años y en la que se conservan algunas pinturas en instituciones como la Pinacoteca de Nuevo León o la Universidad Autónoma de Nuevo León.

En cuanto a España, en el Museo Nacional Centro de Arte Reina Sofía, entidad de referencia para nuestro estudio, encontramos en su colección obras de Remedios Varo, Juana Francisca Rubio y Margarita de Frau, aunque la pintura de esta última está localizada en los depósitos ${ }^{31}$.

La poca presencia de las artistas exiliadas en el Reina Sofía no es una situación que afecte de manera exclusiva a nuestras creadoras sino, más bien, ha sido propiciada por la propia política de adquisiciones del museo visibilizada en un reciente estudio que ha sido presentado como el I Informe sobre la aplicación de la Ley de Igualdad en el ámbito de la cultura dentro del mano competencial del Ministerio de Cultura y Deporte, realizado desde el Observatorio de Igualdad de Género en la Cultura ${ }^{32}$, dependiente del Ministerio de Cultura y Deporte, creado a principios de $2019^{33}$.

En el documento, además de otros aspectos de interés, es reveladora la descripción minuciosa que se hace de la situación de las artes visuales. Para su investigación han seleccionado unos cuantos museos, entre los que se encuentra el Reina Sofía, y han considerado su actuación en materia de adquisiciones y exposiciones, entre el año 2000 y 2018, dejando claro algunos datos interesantes que se convierten en indicadores de la situación en España: de las 3.609 obras nuevas, sin incluir las donaciones, el 75,2\% corresponden a obras producidas por hombres, el 16,6\% a mujeres. El porcentaje restante se reparte entre el 8\%, asignado a "varios autores" y el $0,5 \%$ tiene autoría múltiple. Ahora bien, si observamos el estudio pormenorizado por años, se puede apreciar que en el año 2017 y 2018, los datos han mejorado ya que el $58 \%$ fueron adquisiciones de hombres frente al $42 \%$ de mujeres en el 2017 ; y el 52,6\% frente al 47,4\% de compras de féminas, en el 2018. Estas proporciones hacen referencia

\footnotetext{
${ }^{31}$ Sobre la ubicación de las obras del Reina Sofía cfr. Museo Nacional Centro de Arte Reina Sofía, https://www.museoreinasofia.es/buscar?bundle=\&keyword=Remedios + Varo\&f $\% 5 \mathrm{~B} 100 \% 5 \mathrm{D}=\&$ fecha $=\&$ items per page $=15 \&$ pasados $=1$.

${ }^{32}$ Entre sus prioridades de acción está la realización de estudios estadísticos para mejorar la visibilidad de las mujeres.

${ }^{33}$ Fátima Anllo Vento (dir.), Avance de la publicación, I Informe sobre la aplicación de la ley de Igualdad en el ámbito de la cultura dentro del marco competencial del Ministerio de Cultura y Deporte. (Madrid: Ministerio de Cultura y Deporte, 2020), 151-168. http://www.culturaydeporte.gob.es/dam/jcr:067e3922-191c-4687-b880-39d683a4d8cf/informe-deigualdad.pdf.
} 
al número de obras que pertenecen a autoría única revelándonos, además, que de las 3.312 adquiridas entre el periodo 2000-2018, solo representan a 840 artistas, de las cuales 676 pertenecen a hombres y 164 mujeres. De ellas solo el 6,3\% corresponde a artistas de nacionalidad española, aunque en número de obras, la adquisición supera a las extranjeras.

La disparidad continúa al examinar el tipo (fotografías, esculturas, grabados) que se compra, apreciándose una gran diferencia en el caso de adquisiciones de pinturas: de las 320 compradas, solo 20 pertenecen a mujeres. Finalmente, atendiendo a la cronología, la mayor parte de adquisiciones de féminas están producidas entre 1955 y 1999.

Los datos presentados son significativos en tanto en cuanto demuestran que es necesario seguir reivindicando propuestas con efectividad, porque cómo bien apunta Cristina Nualart "la desproporción de artistas hombres frente a artistas mujeres en el sistema del arte es una realidad constatada repetidamente desde hace varias generaciones" ${ }^{, 34}$. De hecho, esta situación se confirma todavía más cuando analizamos la presencia de las artistas exiliadas, para quiénes la situación se agudiza.

Aunque estas estadísticas muestran la realidad vigente y ejercen la suficiente autoridad para demandar un replanteamiento de los discursos museísticos que podría formalizarse con la compra de nuevas obras, no es menos cierto que esta situación se ha intentado paliar poniendo en marcha acciones que han sido recibidas de modo desigual. En el caso del Reina Sofía la visita Feminismo "que recorre los espacios de la Colección dedicados a las vanguardias históricas y cuestiona el papel y la visibilidad de la mujer en la Historia del Arte a través del análisis de la mujer como productora, receptora y sujeto-objeto de la producción artística" ${ }^{35}$, supone una acción positiva para algunas y, en cambio, para otras "bien podría parecer un maquillaje que disimula la falta de acción

\footnotetext{
${ }^{34}$ Cristina Nualart, "Discriminación positiva, cuotas de género y narrativas feministas en museos de arte contemporáneo", Anales de Historia del Arte, 28 (2018): 433. Junto a este trabajo podríamos enumerar los realizados por la misma autora "Disonancias en el comisariado de exposiciones. Ejemplos de sesgos de género y buenas prácticas en el Museo Nacional Centro de Arte Reina Sofía", Revista AACAdigital, 46 (2019), en línea: http://www.aacadigital.com/index.php o Marta Torregrosa, "Museos y género: una asignatura pendiente", EARI Educación Artística Revista de Investigación, 10 (2019), 184-197, doi: http://dx.doi.org/10.7203/eari.10.14430.

${ }^{35}$ Cfr. Museo Nacional Centro de Arte Reina Sofia, https://www.museoreinasofia.es/visita/tiposvisita/visita-comentada/feminismo.
} 
comisarial para atajar el problema de las salas" ${ }^{36}$, refiriéndose Nualart a la escasa presencia femenina en las paredes del museo. Quizás esta situación ha querido ser subsanada con la reciente creación de dos salas dedicadas al papel de las mujeres durante la Guerra Civil, en las que se muestran obras de Kati Horna, Pitti Bartolozzi, Juana Francisca Rubio y Gerda Taro (Sala 206.09) ${ }^{37}$.

Para el resto de artistas que tuvieron una cierta actividad en España antes de su exilio hay que bucear en las instituciones culturales de sus lugares de origen para localizar alguna tela. En este sentido un caso excepcional lo representa Manuela Ballester, originaria de Valencia, quien en vida donó un conjunto de obras sobre el traje mexicano al Museo Nacional de Cerámica y Artes Suntuarias González Martí, ubicado en Valencia ${ }^{38}$. Posiblemente de todas las artistas, Manuela Ballester sea la más reconocida en su tierra natal donde se conservan obras en el Museo de Arte Contemporáneo "Vicente Aguilera Cerni”, Villafamés; el Instituto valenciano de Arte Moderno; el Museo de la Ciudad; Museo Nacional de Cerámica "González Martî"; o la Real Academia de Bellas Artes de San Carlos.

Menos suerte ha tenido Carmen Cortés, nacida en Barcelona, cuya obra, aunque está presente en alguna institución, ha tenido poca trascendencia. Telas como Retrato de Núria Aguadé Cortés, ubicada en el Museo Nacional de Arte de Cataluña ${ }^{39}$ apenas han sido presentadas en muestras y además de encontrarse en los depósitos, tampoco puede visualizarse la imagen en el catálogo disponible en línea.

\footnotetext{
${ }^{36}$ Cristina Nualart, "Discriminación positiva..., op. cit., pág. 445.

${ }^{37}$ Cfr. Museo Nacional Centro de Arte Reina Sofia, https://www.museoreinasofia.es/coleccion/sala/sala$\underline{20609 .}$.

${ }^{38} \mathrm{El}$ conjunto donado en 1982 está compuesto por 47 piezas, entre pinturas y dibujos y pertenece a una serie que realizó en México, entre 1945 y 1953, en su periodo de exiliada que duró hasta 1959, momento en el que se trasladó a Alemania. Además, el museo también tiene 48 piezas de indumentaria que la propia artista adquirió en mercados del país. La donación sucedió en 1979 y no pudo verse hasta el año 2015. Cfr. Liliane Cuesta Davignon (Comisaria), Dossier de Prensa Manuela Ballester en el exilio. El traje Popular Mexicano (Valencia: Museo Nacional de Cerámica y Artes Suntuarias González Martí, 2015): $\quad$ http://www.culturaydeporte.gob.es/mnceramica/va/dam/jcr:730065f2-9456-4bac-b2565ca36e490d32/dossier-de-prensa-manuela-ballester.pdf.

${ }^{39}$ Véase Museu Nacional d'Art de Catalunya, https://www.museunacional.cat/es/search/content/Carme $\% 20$ Cort $\% \mathrm{C} 3 \% \mathrm{~A} 9 \mathrm{~s}$.
} 


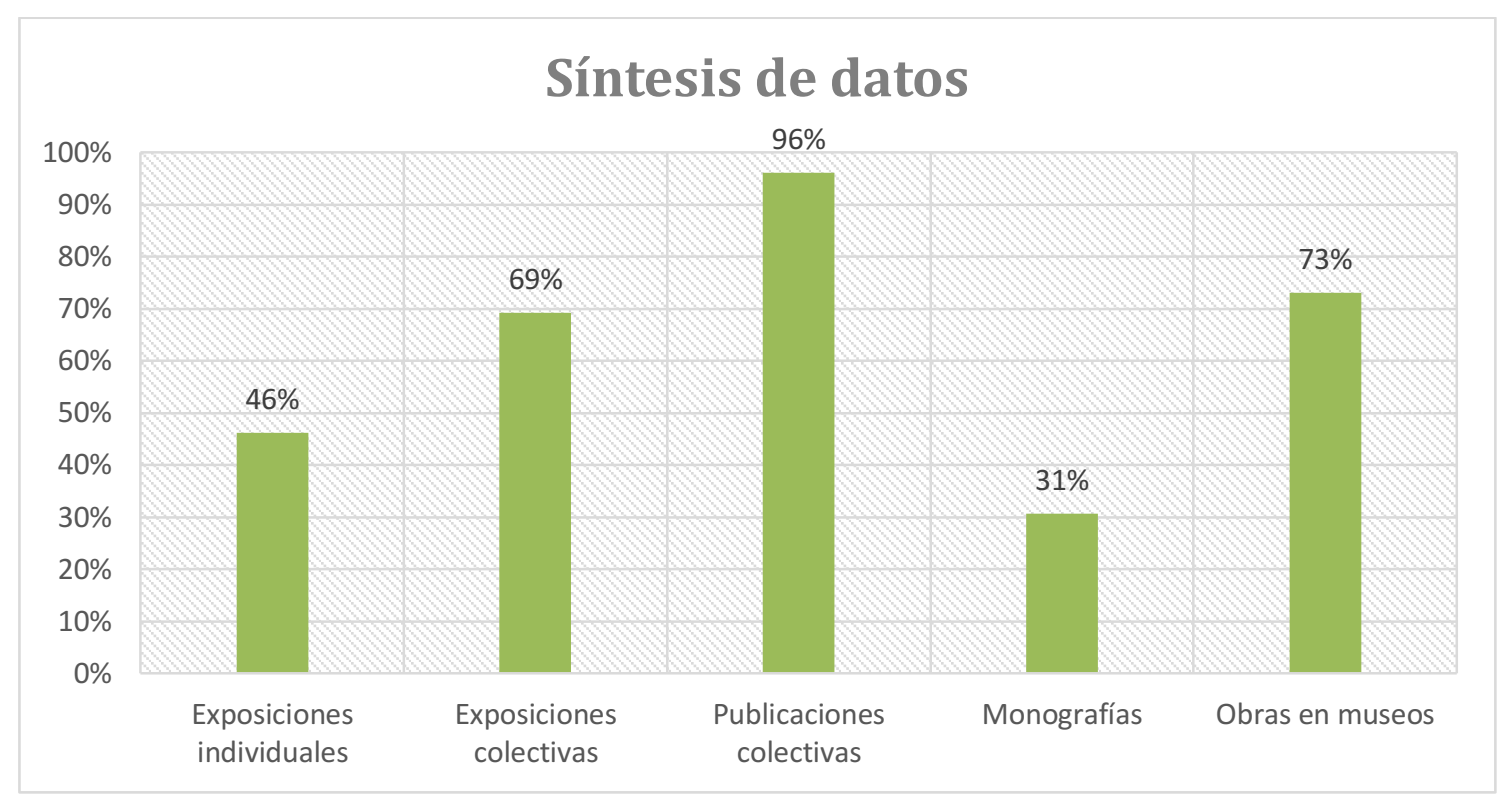

Fuente: Síntesis del análisis realizado de 26 artistas exiliadas en México, y sus descendientes, en libros, muestras individuales y colectivas y museos españoles y mexicanos. Elaboración propia.

\section{BASES DE DATOS EN LÍNEA SOBRE MUJERES ARTISTAS}

Planteada la situación historiográfica, así como el análisis de exposiciones y colecciones museísticas, nos interesa abordar su presencia en internet a través del análisis de las bases de datos existentes ${ }^{40}$.

Una de las primeras iniciativas de este tipo, que se pone en marcha en el año 2007, es la denominada Clara. Database of women artists, en honor a la pintora Clara Peeters. Como indican en su página de inicio: “Clara ${ }^{\circledR}$ is a unique interactive database containing authoritative information on 18,000 women visual artists of all time periods and nationalities. The information in Clara ${ }^{\circledR}$ is drawn from the materials in NMWA's extensive Archives on Women Artists" ${ }^{41}$. Aunque esta base ya no se actualiza, la documentación se basaba, fundamentalmente, en los archivos del Museum of Women in the Art y de nuestras artistas solo recogían el nombre de Remedios Varo.

\footnotetext{
${ }^{40}$ Las bases analizadas han sido seleccionadas porque tratan artistas del siglo XX y el espacio geográfico y temporal de nuestra propuesta.

${ }^{41}$ Cfr. Clara. Datebase of women artists, https://web.archive.org/web/20150317180618/http://clara.nmwa.org/index.php?g=search\&action=home.
} 
Precisamente el National Museum of Women in the Art, ubicado en Washington, fue la primera institución que nació con el claro objetivo de dar visibilidad a las mujeres artistas. Aunque el proyecto surgió en 1981, abrió sus puertas cómo museo en su ubicación actual en 1987. En su colección, conformada por más de 4000 piezas, de las artistas exiliadas la única representada es Remedios Varo que aparece, además, como una de las figuras destacadas del museo con la tela La llamada, que entró a formar parte del acervo gracias a una donación privada ${ }^{42}$.

En la misma línea, pero dedicada a mujeres artistas que están en activo y sin contener una base de datos como tal, se creó en México el Museo de Mujeres Artistas Mexicanas. El proyecto impulsado por Lucero González, cuenta con la representación de las artistas Marta Palau y Lucinda Urrusti que continúan pintando.

En España existe otra iniciativa similar, el denominado Museo de Mujeres Artistas Visuales. Este espacio online está dedicado a "investigar y difundir el legado de las artistas plásticas en la historia de España con el fin de normalizar la inclusión de las artistas españolas en las redes de recuperación de las artistas mujeres en la tradición occidental y en la historia universal" ${ }^{43}$. Ahora bien, aunque no ha promovido una base de datos, la propuesta nos interesa porque tienen intención de incluir un listado, más de mil anuncian, bajo el epígrafe de "Históricas". Si bien éste apartado está en construcción, han insertado el nombre de creadoras desde el siglo X hasta la actualidad y entre ellas, cuatro exiliadas: Manuela Ballester, Elvira Gascón, Paquita Rubio y Remedios Varo ${ }^{44}$.

A nivel internacional, a la ya comentada Clara, otra propuesta de interés para nuestro proyecto es $A W A R E$, organización francesa sin ánimo de lucro, que cataloga el trabajo de mujeres artistas internacionales nacidas entre 1860 y 1972. Las siglas hacen referencia a Archivos de Mujeres Artistas, Investigaciones y Exposiciones, reuniendo las creaciones de artistas del siglo XX en un índice, además de contener la página información sobre conferencias temáticas, visitas e itinerarios. Como bien indican en su

\footnotetext{
${ }^{42} \mathrm{Cfr}$. National Museum of women in the arts, https://nmwa.org/art/artists/remedios-varo/.

${ }^{43} \mathrm{Cfr}$. Museo de mujeres artistas visuales en España, http://www.xn--artistas-visuales-espaolas-2rc.es/.

${ }^{44} \mathrm{Cfr}$. Ibidem, http://www.xn--artistas-visuales-espaolas-2rc.es/antiguas.html.
} 
web: "The primary ambition of AWARE is to rewrite the history of art on an equal footing. Placing women on the same level as their male counterparts and making their works known is long oveerdue" 45 .

AWARE permite una búsqueda por países, movimientos o técnicas y como indican en su web, que puede leerse en inglés y francés, semanalmente hacen nuevas incorporaciones ${ }^{46}$. Originarias de España, únicamente, aparecen 14 nombres: Ángeles Santos, Remedios Varo (incluida además como artista de México junto a Flor Garduño, Leonora Carrington, María Izquierdo, Frida Khalo, Tina Modotti y Alice Rahon), Ouka Leele, Maruja Mallo, Ester Ferrer, Cristina Iglesias, María Blanchard, Pilar Albarracín, Alicia Framis, Dora García, Ángela García Codoñer, Isabel Muñoz y Isabel Oliver Cuevas. De nuevo el proyecto que proponemos ampliará la nómina ya que las únicas exiliadas que recogen son, otra vez, Remedios Varo y Maruja Mallo, exiliada al país argentino.

En cuanto a la información que se despliega en cada entrada individual, considerando la biografía de Remedios Varo ${ }^{47}$, observamos que es bastante completa ya que está firmada por la autora y se añade la bibliografía manejada. Este último aspecto es muy importante porque en otras bases no se incorporan las referencias utilizadas para la reseña disponible. Entre las deficiencias, ofrece un apartado de bibliografía bastante parco tratándose de la artista que nos ocupa, ya que solo citan dos libros.

Como información adicional proponen una pestaña de exposiciones. Sobre Remedios Varo solamente identifican dos, si bien la última que reseñan es del 2019, Adictos a Remedios Varo celebrada en el Museo de Arte Moderno de México, lo que visualiza la actualización del proyecto.

Finalmente pueden conocerse algunas obras, identificadas con su correspondiente copyright. Éste posiblemente sea uno de los grandes obstáculos para la realización de una base de datos en línea sobre artistas del siglo XX, ya que muchas obras están sujetas a derechos de autor, impagables cuando la iniciativa es privada y sin

\footnotetext{
${ }^{45}$ Véase Archives of Women Artists Research and Exhibitions, https://awarewomenartists.com/en/a propos/missions/.

${ }^{46} \mathrm{Cfr}$. Archives of Women Artists Research and Exhibitions, https://awarewomenartists.com/en/decouvrir/ y https://awarewomenartists.com/en/magazine/.

${ }^{47} \mathrm{Cfr}$. Remedios Varo, Archives of Women Artists Research and Exhibitions, https://awarewomenartists.com/en/artiste/remedios-varo/?from=search.
} 
ánimo de lucro. En el caso de $A W A R E$ cuenta con el apoyo de los principales museos de todo el mundo e instituciones de Francia, además de financiación de patrocinadores privados. Como colofón señalar que cuentan, asimismo, con un centro de documentación físico que alberga los propios recursos atesorados por el proyecto a los que se van sumando donaciones.

En último lugar, existe la propuesta de otro nuevo sitio con el nombre de $A$ Space of Their Own, alusión directa al trabajo de Virgina Woolf, Una habitación propia. Según han comunicado en diferentes medios, la iniciativa intentará recopilar un "recurso exhaustivo" de pintoras, grabadoras, escultoras, entre otras, activas en los Estados Unidos y Europa entre los siglos XV y XIX. El proyecto ha nacido como colaboración entre un grupo de investigación de la Universidad de Indiana Bloomington (Estados Unidos) y la fundación Advancing Women Artists, conocida con las siglas AWA. Esta organización, con sede en la ciudad de Florencia, nació con el objetivo claro de identificar, restaurar y exhibir el arte de las mujeres que se encuentran en los almacenes de los museos italianos.

El equipo promotor está convencido que esta iniciativa cubrirá más de lo que otras han podido hacer. Las propias palabras de la directora, Adelheid Gealt, se mueven en esta dirección: "[No other database will] cover as many women from all Europe, with as much information as possible including a robust bibliography and as large an image base as possible" 48 .

Todas las noticias aparecidas en el 2018, anunciaban que ya contaban con más de 600 artistas y que ya se habían puesto en contacto con cuantiosos museos para obtener información. En ese momento, uno de los aspectos que más les había llamado la atención, era que algunas instituciones no tuvieran conocimiento "a mano" de las obras de mujeres. Este hecho ha motivado que uno de los objetivos del proyecto sea sensibilizar a los y las responsables de los museos, en primer lugar, y luego al público, ya que el trabajo, indican, no termina en la base de datos sino comienza en ella.

\footnotetext{
48 Karen Chernick, "A New Illustrated Database for Women Artists the 15th to 19th Centuries", Hyperallergig, 31 de octubre de 2018. En línea: https://hyperallergic.com/468225/a-space-of-their-ownadvancing-women-artists/.
} 
A Space of Their Own tenía previsto ver la luz en el 2019, pero hasta el momento no hemos podido rastrear su publicación ${ }^{49}$. En cualquier caso, el esfuerzo que están realizando será de indudable interés para la comunidad científica y para la sociedad en general, pero de nuevo deja fuera el siglo XX y el XXI.

En España tenemos situamos el modelo más relacionado con nuestro propósito. Desde la Universidad de Zaragoza, la profesora Concha Lomba está liderando el proyecto Las artistas en España, 1804-1939, en el que colaboran profesionales de cuatro universidades españolas: Universidad Complutense de Madrid, Valencia, Sevilla y Zaragoza. Sus objetivos son amplios, pero nos interesa señalar que uno de ellos promueve la creación de una base de datos. Aunque todavía no muestra ningún tipo de contenido, sí que está visible la clasificación a la que irán dotando de información: Arquitectas; Escenógrafas y Figurinistas; Escultoras; Fotógrafas; Ilustradoras y Diseñadoras; y finalmente Pintoras ${ }^{50}$. Además, ya puede conocerse el nombre de algunas de ellas, entre las cuales citan a Remedios Varo, Soledad Martínez, Manuela Ballester, Juana Francisca y Margarita de Frau.

El conjunto reseñado se integra en el libro publicado recientemente, y como resultado del proyecto, Bajo el eclipse. Pintoras en España. 1880-1939, en el que se dedica un capítulo específico a la Segunda República y a la Guerra Civil, identificándose nombres ya conocidos como Remedios Varo, junto a Soledad Martínez, Carmen Cortés, Margarita de Frau y Manuela Ballester, aunque a excepción de las tres primeras, Varo, Martínez y Cortès, la trayectoria de las otras se resume brevemente ${ }^{51}$. Sin embargo, el estudio se presenta como una obra de conjunto, de gran interés, que nos permite trazar una línea del tiempo en la que insertar sus trayectorias, así como los procesos históricos y artísticos, para resolver el desarrollo de las mujeres artistas en el periodo que comprende la publicación, que marca su final cronológico en 1939. Igualmente sugestivos son los anexos que nos permiten visualizar, en cifras, el número de matriculadas en la Escuela Especial de Pintura, Escultura y Grabado entre 18801936, así como su participación en las Exposiciones Nacionales.

\footnotetext{
49 Las últimas noticias que tenemos podemos rastrearlas en la web A space of their own, https://artmuseum.indiana.edu/space-of-their-own/about/index.php.

${ }^{50}$ Cfr. Mujeres artistas en España, 1804-1939, http://maes.unizar.es/artistas.

${ }^{51}$ Concha Lomba Serra, Bajo el eclipse. Pintoras en España, 1880-1939 (Madrid: CSIC, 2019), 227-240.
} 
Este proyecto, de nuevo, es complementario al trabajo que presentamos, pero no se sitúa en el mismo campo de acción ya que al cerrar cronológicamente su ámbito de actuación en el año 1939, deja fuera a muchas otras mujeres.

\section{PROPUESTA DE BASE DE DATOS EN LÍNEA EN ACCESO ABIERTO SOBRE MUJERES ARTISTAS EXILIADAS Y DESCENDIENTES DE LA GUERRA CIVIL}

Los análisis realizados demuestran, por un lado, la pertinencia de la creación de este tipo de iniciativas que incrementen los caminos que conducen al conocimiento de las mujeres artistas y, por otro, la necesidad de seguir implementando nuevas propuestas que supongan otras opciones para redescubrir y amplificar la labor de estas creadoras.

Si la historiografía tradicional las ha olvidado por el hecho de ser mujeres sumado a su condición de exiliadas, la propuesta de creación de una base de datos, integrando también a aquellas que recalaron en otras latitudes como Argentina o Chile, quiere convertirse en el portal capaz de generar nuevos discursos y posibilitar su integración en una Historia del Arte que sigue legitimando relatos hegemónicos. Solo con la recuperación y conocimiento primero, será posible el replanteamiento del discurso del que llevamos hablando a lo largo del texto, sin menospreciar los esfuerzos que hasta aquí se han realizado. Sin ir más lejos, en el caso de las exiliadas, basta con comparar las exposiciones realizadas con motivo del 70 y 80 aniversario del exilio español respectivamente en nuestro país. En la del 70, acometida en el 2009, con el título Después de la alambrada. El arte español en el exilio (1939-1960) ${ }^{52}$, de las 64 obras presentes en la sección de México que representaban a 16 artistas, solo tres eran mujeres: Manuela Ballester, con 3 obras; Elvira Gascón, con 4; y Remedios Varo, con 5, que sumaban en conjunto 12 creaciones del total expuesto en la sección, que suponía casi el 20\% del total representado. En la realizada en 2019, la representación femenina aumentó incluyéndose ahora, además de Gascón y Ballester, a Mary Martín, Marta

\footnotetext{
${ }^{52}$ Jaime Brihuega, Después de la alambrada. El arte español en el exilio (1939-1960). (Madrid: Sociedad Estatal de Conmemoraciones Culturales, 2009).
} 
Palau y María Teresa Toral, además de un texto específico en el catálogo como exponíamos en líneas anteriores ${ }^{53}$.

La propuesta de creación de la base de datos sobre exiliadas vendría, también, a poner en valor sus propios archivos personales gestionados ahora por sus familiares directos, como el caso de Elena Verdes-Montenegro, atesorado por su nieto Valentín Navarro; el de las hermanas Ballester, distribuido entre México, Alemania y España y conservados por sus hijos e hijas respectivamente, o el de Regina Raull, recientemente fallecida, que ella misma resguardaba en su domicilio particular donde además tenía instalado su estudio, compuesto por más de 2000 notas de prensa perfectamente clasificadas por años, a las que hay que sumar documentos personales, catálogos de exposiciones y un conjunto importante de pinturas ${ }^{54}$.

Igualmente, nuestra iniciativa se convertiría en un canal de proyección de otros repertorios integrados ya en instituciones públicas pero que fueron originados por las propias artistas o sus familiares como el caso del de Elvira Gascón, que pasó a ser gestionado por El Colegio de México gracias a la donación de su hija Guadalupe Fernández Gascón ${ }^{55}$.

Algo similar ha ocurrido con la información relacionada con la pintora catalana Montserrat Aleix. Realmente, toda la documentación de esta artista -catálogos de exposiciones, noticias de prensa, adquisiciones de sus pinturas...étc- se guardaba en el archivo de la Galería Pecanins, fundada en 1964 por sus hijas Montserrat, María Teresa y Ana María, donde se promovieron varias exposiciones de Aleix ${ }^{56}$. En el año 2009, tras el cierre de sus puertas, toda la documentación de la galería pasó al archivo del Museo Universitario de Arte Contemporáneo, conocido como MUAC, de la Universidad

\footnotetext{
${ }^{53}$ El texto se ha mencionado en la nota 15.

${ }^{54}$ La pintora falleció a finales de 2019. Consideramos que sería interesante que el archivo pasara a formar parte de alguna institución pública de la Ciudad de México.

${ }^{55}$ Una primera parte del actual acervo fue donado en el 2001, un año después de la muerte de la artista, y está compuesto por 74 cajas con libros ilustrados, correspondencia, ejemplares de suplementos culturales de diversos diarios, revistas, catálogos de exposiciones y folletos. A este conjunto se sumó, en el año 2003, otra donación en la que también se incluyeron tarjetas postales y de felicitación, fotografias, así como carpetas con retratos de músicos y escritores, entre otros materiales. Cfr. Mónica Mateos-Vega, “Enriquecen el acervo de Elvira Gascón en el Colmex", La Jornada, 11 de febrero de 2003.

${ }^{56}$ Sobre la historia de la galería cfr. Luis Carlos Emerich, Galería Pecanins, la siempre vivaz (México: D.G. Ediciones/Turner libros, 2000.
} 
Nacional Autónoma de México creado justo un año antes ${ }^{57}$. Como indican desde el propio museo: "La mayor parte de este fondo está organizado por expedientes de artistas y contiene también documentos administrativos y de gestión de la galería, así como una amplia colección de fotografías, diapositivas y carteles de sus exposiciones" ${ }^{, 58}$.

Finalmente, uno de los últimos compendios incorporado a un organismo público ha sido el de la pintora madrileña Julia Giménez Cacho ${ }^{59}$. La donación se hizo al Ateneo Español de México, en el marco de la presentación del libro escrito por Luis Giménez Cacho ${ }^{60}$ y la organización de una exposición sobre la pintora con una pequeña selección de sus telas ${ }^{61}$ en el año 2016.

En resumen, la creación de una nueva base de datos específica sobre mujeres artistas exiliadas viene motivada por la escasa información que se presenta en compendios generales de arte; la poca transferencia de la investigación que se ha hecho de sus trayectorias artísticas a través de exposiciones; $\mathrm{y}$, finalmente, su poca representación en museos e instituciones culturales tanto de España como de México, principales espacios para su difusión y de contacto con la sociedad en general.

En base a lo expuesto, los principales objetivos se concretarían en los siguientes:

- Poner en valor el trabajo creativo de las artistas exiliadas en América de manera más efectiva.

\footnotetext{
${ }^{57}$ Sobre la creación de este museo cfr. Olivier Debroise, Graciela de la Torre y Cuauhtémoc Medina, MUAC, 2008-2015 (México: MUAC, 2015).

${ }^{58}$ Véase Museo Universitario de Arte Contemporáneo, https://muac.unam.mx/espacios.

${ }^{59}$ Sobre esta pintora cfr. Yolanda Guasch Marí, “Artistas transterradas: Julia Giménez Cacho”, coord. por Adalberto Santana y Aurelio Velázquez, Docencia y cultura en el exilio republicano español (México: Universidad Nacional Autónoma de México, 2015), 143-153.

${ }^{60}$ El libro fue escrito por el marido de la pintora a su muerte. En él se recogen los pasajes personales y profesionales más importantes de sus vidas: su compromiso en la Guerra Civil, los motivos que les llevaron a salir de España, su paso por Estados Unidos, su llegada a México y el inicio de Julia Giménez Cacho en la pintura. Cfr. Luis Giménez Cacho, Dos vidas. Memorias (México: El Colegio de México/Ateneo Español de México, 2014).

${ }^{61}$ Desde su muerte en el año 2000 ha sido la primera muestra que se ha realizado. Cfr. Ateneo Español de México, http://www.ateneoesmex.com/inicio/presentacion-de-dos-vidas-memorias-de-luis-gimenezcacho-inauguracion-de-la-muestra-de-pintura-de-julia-gimenez-cacho/.
} 
- Ofrecer un corpus de información y documentación sistematizado, de fácil consulta y útil para localizar datos importantes sobre cada una de ellas que sirva, además, como punto de partida para acceder a sus vidas y obras.

-Generar datos que permitan realizar informes estadísticos que, a la vez, sirvan para crear el empuje necesario para la creación de nuevos recorridos que las fortalezca en los discursos expositivos.

Aunque en proceso de publicación, contamos con los resultados del proyecto mencionado, realizado al amparo de la Universidad Nacional Autónoma de México, en el que a través de una ficha catalográfica se ha recogido de cada artista los siguientes apartados: Nombre completo y nombre artístico; Lugar y fecha de nacimiento; Técnicas; Exposiciones, colectivas e individuales y el nombre de las obras expuestas; Ubicación de las obras más representativas; Breve semblanza biográfica; Premios, distinciones y becas; Críticas de arte; Información de interés; Bibliografía y hemerografía; Filmografía y sitios web y blogs.

Nuestra propuesta arranca, por lo tanto, en las bases de datos existentes, pero, también, establecemos el punto de partida en los epígrafes planteados en la ficha catalográfica mencionada. Dado el amplio número de artistas que podemos llegar a implementar, la base de datos se visualizaría a modo de diccionario, desplegándose el nombre completo de cada artista y el lugar de nacimiento y defunción. De hecho, se ofrecerían otros motores de búsqueda como el lugar de nacimiento.

Asimismo, teniendo en cuenta los modelos analizados y la propia metodología aplicada en el proyecto de investigación citado, cada una de las creadoras contendría los siguientes epígrafes:

- Breve semblanza biográfica en la que se aporten los datos más relevantes para generar el suficiente interés para seguir profundizando en su estudio.

- Bibliografía completa: Este será un apartado que siempre estará enriqueciéndose ya que permitirá visualizar de manera rápida las investigaciones realizadas para cada una de las artistas. En este sentido, la que ahora presenta mayor dificultad es únicamente Remedios Varo de quien se genera, anualmente, muchísima literatura científica. 
- Catálogo de obras: este apartado cobra especial importancia porque la correcta identificación de telas y su ubicación, permitirá conectar instituciones con intereses comunes, tanto nacionales como internacionales. En nuestra investigación, como ya adelantamos, hemos podido localizar un importante número de telas que servirían para rediseñar discursos museísticos o implementar exposiciones temporales, teniendo en cuenta que las obras de muchas de las artistas nombradas son poco conocidas en las propias instituciones donde se integran o, también, porque están en colecciones que no han logrado ponerlas en valor. Por poner solo un ejemplo, la obra de María Teresa Toral está fundamentalmente representada en la Colección Pago en Especie ${ }^{62}$, dependiente de la Secretaría de Hacienda y Crédito Público de México. Aunque este acervo cuenta con su propio museo para ser difundir la colección, la realidad es que un número considerable de telas, entre las que se encuentran las de la propia Toral, se localizan en dependencias de organismos públicos cumpliendo una función decorativa, lo que limita su reconocimiento y valoración.

Igualmente, se incorporarán aquellas obras que están en colecciones privadas conocidas y, también, se abrirá un espacio para la colaboración de la sociedad. En este apartado contribuiríamos a abrir la plataforma a la ciudadanía que podría registrar las obras que tengan en su poder, contribuyendo a la localización de nuevas creaciones. En el caso que nos ocupa, este epígrafe sería uno de los más importantes, debido a que la mayoría de las pinturas de las exiliadas se encuentran en manos de particulares ${ }^{63}$.

\footnotetext{
${ }^{62}$ Esta iniciativa surgió a propuesta de un grupo de artistas que en 1957, encabezados por el pintor David Alfaro Siqueiros, le solicitaron al entonces Director del Impuesto sobre la Renta, Hugo B. Margáin, la opción de pagar sus impuestos mediante obra plástica de su autoría. La propuesta fue aprobada y al programa se sumaron algunos de los más importantes artistas del país como Diego Rivera, Rufino Tamayo y Raúl Anguiano, lo que marcó el inicio de un innovador programa fiscal que ofrece a los creadores (mexicanos o extranjeros radicados en México) la posibilidad de cumplir sus obligaciones tributarias con su producción artística. Hoy en día el programa Pago en Especie conforma una de las más importantes colecciones de arte moderno y contemporáneo en México y continúa siendo un referente internacional en cuanto a la configuración de acervos públicos y de vanguardia tributaria en apoyo a los artistas. Formalizado en un Decreto Presidencial de 1975, y aunque está integrado principalmente por pintura y escultura, ha ido modificándose para modernizar su operación y actualmente el programa también incluye formatos como fotografía, instalación y arte digital, entre otros. Para conocer más sobre la colección cfr. AA.VV, 200 Años de la Hacienda Pública en México (1810-2010). (México: Secretaría de Hacienda y Crédito Público, 2010).

63 En esta línea de trabajo se sitúa la plataforma Colabora, elaborada en el marco del proyecto "Patrimonio artístico y relaciones culturales entre Andalucía y América del Sur" (HAR2014-57354-P), financiado por el Ministerio de Economía y Competitividad del Gobierno de España. Cfr. Colabora con nosotros, https://colabora.andaluciayamerica.com/.
} 
- Relación de exposiciones: Este apartado permite generar, entre otros, informes cuantitativos y cualitativos sobre la fortuna expositiva de las artistas. A la vez, la correcta identificación de las muestras no permite rastrear las críticas a sus obras, así como reconocer nuevas creaciones a través de los catálogos.

- Archivo fotográfico: finalmente se propone un epígrafe en el que se integren imágenes, tanto personales como profesionales, que permitan estudiar y analizar los ámbitos de relaciones sociales y culturales de las artistas exiliadas.

El resultado final que planteamos, es un corpus documental, fotográfico y biográfico de sumo interés para otros investigadores o investigadoras que quieran releer a estas artistas. Somos conscientes que para algunas de ellas publicar mucha de la documentación relacionada será una tarea difícil porque, como ya mencionamos, está sujeta a derechos de autor, pero la posibilidad de citar obras y geolocalizarlas en las instituciones que son públicas ya sería una aportación de enorme importancia. Igualmente, resultaría interesante enumerar la bibliografía y situarla en los repositorios disponibles. También, otro de los grandes desafíos a los que habrá que hacer frente, será evidentemente la financiación, limitación con la que se han encontrado muchos de los antecedentes comentados que, evidentemente, permita sostener el proyecto a largo plazo. En la actualidad existe algún software libre, como "Omeka", que se ajusta a nuestros objetivos y que, en línea con las nuevas actuaciones de sostenibilidad, permitiría su mantenimiento en el tiempo.

El proyecto, a la vez, presenta algunas fortalezas significativas como ofrecer nuevas oportunidades de intercambio y diálogo. En este sentido, la participación ciudadana se convierte en una de las claves de éxito, al fomentar el trabajo colaborativo, conectar la investigación con la sociedad y, a la vez, contribuir a facilitar el conocimiento de toda la información y/o documentación a la que no se tiene fácil acceso porque está localizada en archivo físicos lejos del espacio de trabajo donde nos ubicamos realizando la investigación o, simplemente, porque se ha ido acumulando en repositorios personales. Esta idea está en sintonía con las denominadas plataformas abiertas que buscan, precisamente, poner en valor toda aquella investigación que hemos acumulado a lo largo de años de estudio y puede ser útil para otras nuevas 
investigaciones ${ }^{64}$. En esta línea se sitúa el análisis realizado por Maurizio Toscano ${ }^{65}$ sobre las posibilidades que ofrecen varias plataformas online implementadas por equipos de investigación y creadas para publicar un conjunto de datos que no son públicos, reunir nuevos a través de la participación externa y colaborar con otros equipos.

\section{CONCLUSIONES}

A modo de conclusiones, en este texto hemos definido el espacio cultural donde imbricamos nuestra investigación y hemos analizado la situación en relación a la puesta en valor de las mujeres artistas del periodo, identificando las lagunas existentes y, por tanto, los caladeros de investigación. A partir de aquí, proponemos una nueva base de datos que se concibe en un doble sentido: como una pantalla de proyección de las artistas exiliadas y, al tiempo, como un territorio de nuevas investigaciones al nutrirse, además, de las aportaciones externas que pueda hacer la propia ciudadanía. Propuesta colaborativa que permite definir un proyecto siempre abierto pero que, a la vez, supone transferencia directa del conocimiento y participación de segmentos sociales que, desde distinta formación y localización, construyen patrimonio.

Además, aunque acotamos, inicialmente, el ámbito de acción a las artistas españolas exiliadas tras el conflicto español a América, proponemos la ampliación, en una segunda fase, a las artistas en general emigradas a lo largo del siglo XX, aunque siempre manteniendo América como espacio geográfico receptor.

Para dar forma a nuestra propuesta nos servimos de las posibilidades derivadas de lo que denominamos la era digital, la cual nos ha proporcionado, y nos sigue proveyendo, de herramientas capaces de permitir la transferencia del conocimiento académico con acciones diferentes que permiten, además, eliminar barreras. En este sentido, la base de datos online que proponemos, en acceso abierto, vendría a completar

\footnotetext{
${ }^{64}$ De hecho las convocatorias de proyectos de investigación tanto nacionales como internacionales ya exigen que los datos que se deriven del proyecto tienen que estar disponibles en un formato csv y convenientemente descritos y etiquetados con metadatos para su reutilización por la comunidad investigadora.

${ }^{65}$ Maurizio Toscano, "Where the researcher cannot get: open platforms to collaborate with citizens on cultural heritage research data", ed. Esteban, Romero Frías y Lidia, Bocanegra Barbecho, Ciencias Sociales y Humanidades Digitales Aplicadas. (Granada: Universidad de Granada, 2018), 538-561.
} 
las ya mencionadas y analizadas, absorbiendo sus potencialidades pero, en paralelo, abriendo nuevas posibilidades, lo que supondría llenar otra pequeña laguna en el estudio general de las mujeres artistas, porque como bien apunta la comisaria Maura Reilly, partidaria de lo que llama el "activismo curatorial", "hasta que no haya igualdad de género en el mundo del arte, las exposiciones [o cualquier otra acción] exclusivamente de mujeres continuarán siendo necesarias" ${ }^{\text {66 }}$.

En definitiva, aportamos una herramienta válida para ampliar el conocimiento del tema tratado que, a su vez, se cimenta en estudios previos que avalan la necesidad de la misma y que refrendan las posibilidades nuevas de conocimiento con su construcción.

\section{BIBLIOGRAFÍA}

AA.VV. Museo del Palacio de Bellas Artes. México: CONACULTA, 2012.

AA.VV. 200 Años de la Hacienda Pública en México (1810-2010). México: Secretaría de Hacienda y Crédito Público, 2010.

AA.VV. La pintora Soledad Martínez y sus coleccionistas. Valencia: Talleres Gráficas Ripoll, 1991.

Aldama, José Ignacio. “La colección Kaluz”. En La colección Kaluz, editado por Elena Horz Balbás, 12-13. México: Horz Asociados, 2018.

Anllo Vento, Fátima (Dir.). Avance de la publicación, I Informe sobre la aplicación de la ley de Igualdad en el ámbito de la cultura dentro del marco competencial del Ministerio de Cultura y Deporte. Madrid: Ministerio de Cultura y Deporte, 2020.

Brihuega, Jaime (dir.). Después de la alambrada. El arte español en el exilio (1939-1960). Madrid: Sociedad Estatal de Conmemoraciones Culturales, 2009.

Cerro Herrero, Susana del y Esther Meneses Ruiz de los Paños. "Iniciativas paravla difusión del arte en Twitter en España. El proyecto de @UnDiaUnaObra". ArtyHum, Revista Digital de Artes y Humanidades, 1 (2015): 73-90.

Chernick, Karen. "A New Illustrated Database for Women Artists the 15 th to $19^{\text {th }}$ Centuries". Hyperallergig, 31 de octubre de 2018. En línea: https://hyperallergic.com/468225/a-space-of-their-own-advancing-womenartists/.

Cuesta Davignon, Liliane (Comisaria). Dossier de Prensa Manuela Ballester en el exilio. El traje Popular Mexicano. Valencia: Museo Nacional de Cerámica y Artes Suntuarias González Martí, 2015.

\footnotetext{
${ }^{66}$ Tomado del artículo de Cristina Nualart, "Discriminación positiva..., op. cit., 446.
} 
Cueva, Almudena de la, y Margarita Márquez Padorno (eds.). Mujeres en vanguardia, La residencia de Señoritas en su centenario [1915-1936], Madrid: Residencia de Estudiantes, 2015.

Debroise, Olivier, Graciela de la Torre y Cuauhtémoc Medina, MUAC, 2008-2015. México: MUAC, 2015.

Eder, Rita. Marta Palau. La intuición y la técnica. Michoacán: Gobierno de Michoacán, 1985.

Emerich, Luis Carlos. Galería Pecanins, la siempre vivaz. México: D.G. Ediciones/Turner libros, 2000.

Espinasa, José María, y Teresa Olabuenaga (Textos). Colección plástica del Ateneo Español de México. 70 Años de pluralidad. México: Ateneo Español de México A.C., 2018.

Espinosa Campos, Eduardo. Lucinda Urrusti. Pintora de la luz. México: Círculo del Arte, 2008.

Gaitán Salinas, Carmen. Las artistas del exilio republicano español. El refugio latinoamericano. Madrid: Cátedra, 2019.

Gaitán Salinas, Carmen. "Ellas también fueron artistas: las españolas del exilio republicano en América Latina". En 1939. Exilio republicano español, coordinado por Juan Manuel Bonet, 445-452. Madrid: Ministerio de Justicia, 2019.

García, Manuel (Ed.). Homenatge a Manuela Ballester. Valencia: Generalitat Valenciana, Consellería de Trabajo y Asuntos Sociales, Dirección General de la Mujer, 1996.

Giménez Cacho, Luis. Dos vidas. Memorias. México: El Colegio de México/Ateneo Español de México, 2014.

Gómez-Blesa, Mercedes. Modernas y Vanguardistas. Las mujeres-faro de la Modernidad. Madrid: Huso Ensayos, 2019.

Guasch Marí, Yolanda. “Artistas transterradas: Julia Giménez Cacho”. En Docencia y cultura en el exilio republicano español, coordinado por Adalberto Santana y Aurelio Velázquez, 143-153. México: Universidad Nacional Autónoma de México, 2015.

Guasch Marí, Yolanda y Montañés, María José. María Teresa Toral. Obra Gráfica, Alcalá la Real: Asociación Enrique Toral y Pilar Soler, Ayuntamiento de Andújar, 2012.

Lomba Serrano, Concha. Bajo el eclipse. Pintoras en España, 1880-1939. Madrid: CSIC, 2019.

Luquin Calvo, Andrea. Remedios Varo: el espacio y el exilio. Alicante: Centro de Estudios sobre la mujer/Universidad de Alicante, 2009.

Mateos-Vega, Mónica. "Enriquecen el acervo de Elvira Gascón en el Colmex". La Jornada, 11 de febrero de 2003. 
Muñoz, Pilar. "Las publicaciones y la investigación sobre mujeres artistas en España", Revista de Estudios de las Mujeres, 3 (2015): 317-338.

Nonaka, Masayo. Remedios Varo: Los años en México. México: Ediciones RM, 2012.

Nualart, Cristina. "Discriminación positiva, cuotas de género y narrativas feministas en museos de arte contemporáneo". Anales de Historia del Arte, 28 (2018): 431446. doi: https://doi.org/10.5209/ANHA.61624.

Nualart, Cristina. "Disonancias en el comisariado de exposiciones. Ejemplos de sesgos de género y buenas prácticas en el Museo Nacional Centro de Arte Reina Sofia”, Revista AACAdigital, $46 \quad$ (2019). En línea: http://www.aacadigital.com/index.php.

Ramírez Sánchez, Mauricio César. Elvira Gascón. La línea de una artista en el exilio. México: El Colegio de México, 2014.

Riaño, Peio H. Las invisibles. ¿Por qué el Museo del Prado ignora a las mujeres? Madrid: Capitán Swing, 2020.

Rivera, Magnolia. Trampantojos. El círculo en la obra de Remedios Varo. México: Siglo XXI, 2005.

Rodríguez Ortega, Nuria. "Humanidades Digitales, Digital Art History y cultura artística: relaciones y desconexiones", Artnodes, 13 (2013): 16-25. doi:10.7238/a.v0i13.2017.

Torregrosa, Marta."Museos y género: una asignatura pendiente”. EARI Educación Artística Revista de Investigación, 10 (2019): 184-197. doi: http://dx.doi.org/10.7203/eari.10.14430.

Toscano, Maurizio. "Where the researcher cannot get: open plat-forms to collaborate with citizens on cultural heritage research data". En: Ciencias Sociales y Humanidades Digitales Aplicadas, editado por Esteban, Romero Frías y Lidia, Bocanegra Barbecho, 538-561. Granada: Universidad de Granada, 2018.

Ulacia, Manuel. "Los pintores del exilio español en México". En 50 Aniversario del Exilio Español (1939-1989), editado por AA.VV, 7-12. México: Museo de San Carlos, 1989. 